\title{
Novel growth techniques for the deposition of high-quality perovskite thin films
}

Annie Ng, Zhiwei Ren, Gang Li, Aleksandra B. Djurišić, Charles Surya

Annie Ng, Zhiwei Ren, Gang Li, Aleksandra B. Djurišić, Charles Surya, "Novel growth techniques for the deposition of high-quality perovskite thin films," Proc. SPIE 10533, Oxide-based Materials and Devices IX, 105331Y (23 February 2018); doi: 10.1117/12.2302468

SPIE. Event: SPIE OPTO, 2018, San Francisco, California, United States 


\title{
Novel Growth Techniques For The Deposition of High Quality Perovskite Thin Films
}

\author{
Annie $\mathrm{Ng}^{\mathrm{a}}$, Zhiwei Ren ${ }^{\mathrm{a}}$, Gang Li ${ }^{\mathrm{a}}$, Aleksandra B. Djurišić ${ }^{\mathrm{b}}$, and Charles Surya ${ }^{*}, \mathrm{c}$ \\ ${ }^{a}$ Department of Electronic and Information Engineering, The Hong Kong Polytechnic University, \\ Hong Kong, P.R. China, ${ }^{b}$ Dept. of Physics, University of Hong Kong, Hong Kong, P.R. China,

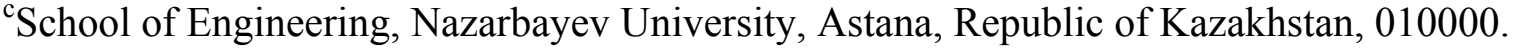

\begin{abstract}
We present investigations on the growth of high quality $\mathrm{CH}_{3} \mathrm{NH}_{3} \mathrm{PbI}_{3}$ (MAPI) thin films using both vapor and solution techniques. Recent work on perovskite film growth indicates critical dependencies of the film quality on the nucleation and crystallization steps requiring: i.) uniform distribution of nucleation sites; and ii.) optimal crystallization rate that facilitates the growth of a compact, continuous film with low density of pinholes. Our work shows that the hybrid chemical vapor deposition technique (HCVD) technique is well suited for the deposition of evenly distributed nucleation sites and the optimization of the crystallization rate of the film through detailed monitoring of the thermal profile of the growth process. Signficant reduction in the defect states is recorded by annealing the perovskite films in $\mathrm{O}_{2}$. The results are consistent with theoretical studies by $\mathrm{Y}$ in et al. ${ }^{1}$ on $\mathrm{O}$ and $\mathrm{Cl}$ passivation of the shallow states at the grain boundary of MAPI. Their work provides the theoretical basis for our experimental observations on the passivation of shallow states by oxygen annealing. High quality films were achieved through detailed management of the carrier gas composition and the thermal profile of the nucleation and crystallization steps.
\end{abstract}

Keywords: high efficiency perovskite solar cells, hybrid chemical vapor deposition, oxygen annealing

\section{INTRODUCTION}

The present worldwide power consumption is approximately 18 TW which is expected to grow by $30 \%$ by $2035 .^{2}$ Continued dependence on fossil fuels for power generation will lead to devastation in the environment. The International Energy Agency had projected that roughly $50 \%$ of the net increase in electricity generation will come from renewables. ${ }^{3}$ Thus, it is crucial to develop highly cost-effective and efficient photovoltaic cells (PVCs) to meet the global energy demands for the $21^{\text {st }}$ Century. Organic-inorganic perovskite thin films, as a new PV material, have drawn significant attention due to the dramatic development of high efficiency perovskite solar cells (PSCs). Within a decade since the first report of PSC devices, the efficiency had increased from $3.81 \%{ }^{4}$ to a record $22.7 \%{ }^{5}$ at the time of the compilation of this manuscript. The key driving forces for such tremendous achievements include: i.) excellent physical properties such as high absorption coefficients ${ }^{6}$, extremely long carrier diffusion lengths ${ }^{7}$ and tunable bandgaps; ${ }^{8}$ ii.) development of techniques for the growth of high quality perovskite films including the vapor assisted solution process, ${ }^{9}$ HCVD technique, ${ }^{10}$ solvent engineering, ${ }^{11}$ and the vacuum-assisted growth techniques ${ }^{12}$... etc.; iii.) development of highly efficient device structures, for instance the planar structure, mesoporous structure and inverted structure ${ }^{13,14}$; and iv.) development of high-quality electron transport layer (ETL) and hole transport layer (HTL) for efficient collection and transport of photo-generated carriers. ${ }^{15,16}$ Of all the different factors listed above, the growth of high quality perovskite thin films arguably has the biggest impact on the development of the PSCs thus far.

The solvent engineering technique was reported by Jeon et al. ${ }^{17}$ who used a mixed solvent of $\gamma$-butyrolactone (GBL) and dimethylsulphoxide (DMSO) followed by toluene drop-casting that leads to extremely uniform and dense perovskite layers via a $\mathrm{CH}_{3} \mathrm{NH}_{3} \mathrm{I}-\mathrm{PbI}_{2}-\mathrm{DMSO}$ intermediate phase with $\mathrm{GBL}$ functioning purely as a solvent. It was shown that at the initial stage the film is composed of MAI and $\mathrm{PbI}_{2}$ dissolved in the DMSO/GBL solvent mixture. With the evaporation of GBL from the film, a complex consisting of $\mathrm{CH}_{3} \mathrm{NH}_{3} \mathrm{I}-\mathrm{PbI}_{2}-\mathrm{DMSO}$ is formed. Toluene, which acts as an anti-solvent, is added to the film during the spinning process and induces a super-saturation condition resulting in the 
immediate freezing of the constituents due to the quick removal of the excess DMSO solvent. This gives rise to a uniform and transparent thin layer of $\mathrm{MAI}-\mathrm{PbI}_{2}-\mathrm{DMSO}$ across the substrate. The formation of this $\mathrm{MAI}-\mathrm{PbI}_{2}-\mathrm{DMSO}$ complex is crucial for the growth of the compact and uniform perovskite layer. It was determined that the function of the DMSO is to retard the pre-mature reaction between and $\mathrm{PbI}_{2}$ and, thereby, facilitating the even distribution of the key constituents (MAI and $\mathrm{PbI}_{2}$ ) over the entire substrate. Finally, upon annealing at $100^{\circ} \mathrm{C}$, a homogeneous MAPI film is formed.

A vacuum-flash solution processing (VASP) technique was reported by Li et al. ${ }^{18}$ for the growth of mixed perovskites that enables the sudden and well-controlled removal of solvent and thereby resulting in a super-saturated condition and facilitates the formation of evenly distributed nucleation sites consisting of a Lewis acid-base type adduct of perovskite precursor phase. Upon thermal annealing, a crystalline film of excellent electronic quality can be formed on a variety of substrates.

Comparing the two techniques indicates that the quality of the perovskite film critically depends on the initial nucleation and the subsequent crystallization steps. The nucleation process must enable the deposition of an evenly distributed nucleation sites. In both techniques, this was achieved by a rapid "freezing" process by creating a supersaturation condition either through the application of an anti-solvent or the controlled removal of the solvent using a flash vacuum technique. A slow nucleation process will lead to pre-mature crystallization resulting in the coalescence of the nuclei into large crystallites. This will result in the formation of highly non-uniform films with high concentration pinholes.

In this paper we present a novel HCVD technique for the growth of MAPI layers inside a Si oxidation furnace. This is a key advantage for this technique as Si processing equipment are highly developed, cost-effective, and supports batch processing. The process design ensures elimination of premature crystallization as the precursors are completely separated in the initial phase and, thereby, excellent uniformity in the nucleation sites is assured. It is shown that through detailed control of the thermal profile of the growth process, highly compact and uniform MAPI films can be grown. We will also present systematic investigation in the concentration of defect states in the MAPI films through exposure to $\mathrm{O}_{2}$ during growth.

\section{RESULTS AND DISCUSSION}

The experimental setup for the HCVD process is shown in Figure 1. First, a layer of $\mathrm{PbI}_{2}$ is spin-coated onto a glass $/ \mathrm{FTO} / \mathrm{TiO}_{2}$ substrate and placed inside the furnace. The MAI powder, as a source, is kept at $T_{M A I}=180^{\circ} \mathrm{C}$ and, with the substrate placed downstream to the MAI, a carrier gas is used to transport the sublimated MAI to the sample which is maintained at an elevated substrate temperature, $T_{S}$, for the crystallization of the MAPI thin films. The growth temperature

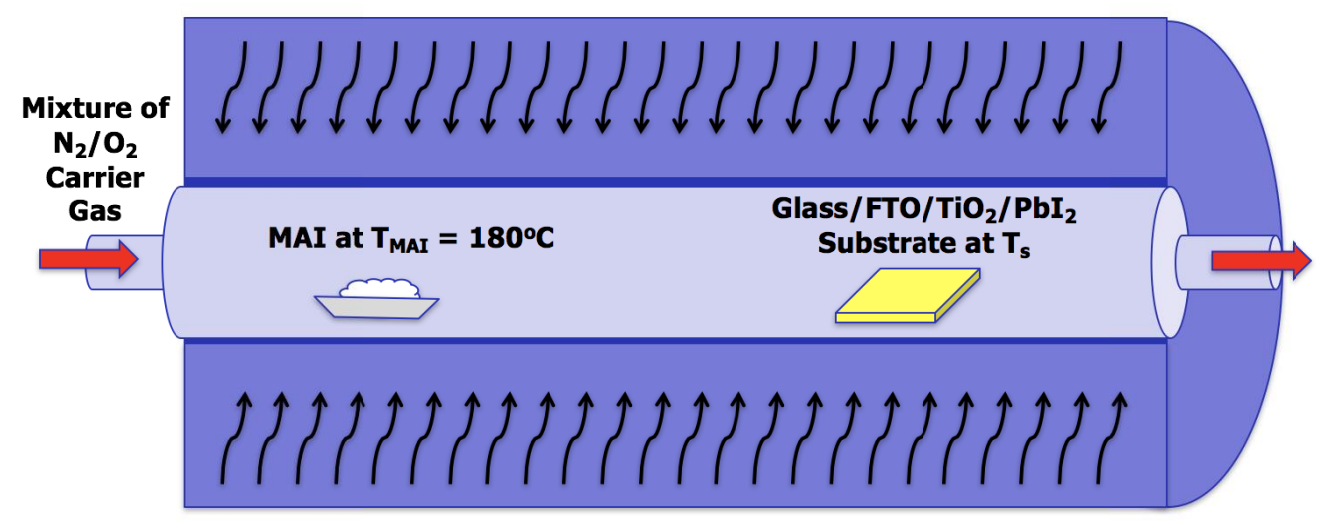

Figure 1. Experimental setup for the HCVD growth of perovskite thin films 
for the material was systematically varied and the optoelectronic properties of the materials and the resulting devices were characterized in detail and the data were used for the optimization of the process. Our results show that the optimal growth temperature is $\sim 165^{\circ} \mathrm{C}^{19}$ which is substantially higher than the typical reaction temperatures used in the solution growth techniques that are commonly limited to $90^{\circ} \mathrm{C}-100^{\circ} \mathrm{C}^{20}$. It is noted that at temperatures $>100^{\circ} \mathrm{C}$, for conventional solution processed perovskites, significant decomposition of the MAPI, due to the sublimation of MAI from the film, is observed ${ }^{20}$. In the HCVD process, the carrier gas is saturated with MAI which suppresses the sublimation of MAI from the film, and thus a higher crystallization temperature can be used without suffering any film degradation. A higher growth temperature is beneficial to atomic motion during the crystallization process and thereby enhances the grain size of the MAPI layer.

To investigate the impact of the composition of the carrier gas on the film quality, we have systematically varied the ratio of $\mathrm{O}_{2} / \mathrm{N}_{2}$ in the carrier gas from $0 \%$ to $25 \%$. Planar devices were fabricated using the MAPI films grown under different carrier gas compositions and the optoelectronic properties of the devices are summarized in Table 1. Strong dependencies of the device PCEs on the carrier gas composition are observed. Our experimental results indicate that using the optimal carrier gas composition of $\mathrm{N}_{2} / \mathrm{O}_{2}(85 \% / 15 \%)$ leads to significant enhancement in the PCE of the devices.

Table 1: The summary of the photovoltaic performance of devices with the MAPI grown in different ambient. The values were averaged from 6-12 devices.

\begin{tabular}{|c|c|c|c|c|}
\hline $\begin{array}{c}\text { Carrier Gas } \\
\text { Composition }\end{array}$ & $\begin{array}{c}\boldsymbol{V}_{\boldsymbol{O C}} \\
(\mathbf{V})\end{array}$ & $\begin{array}{c}\boldsymbol{J}_{\boldsymbol{S C}} \\
\left(\mathbf{m A} / \mathbf{c m}^{2}\right)\end{array}$ & $\mathbf{F F}$ & $\begin{array}{c}\text { Efficiency } \\
(\mathbf{\%})\end{array}$ \\
\hline $\mathrm{N}_{2} / \mathrm{O}_{2}$ & 0.91 & 21.4 & 0.57 & 11.1 \\
$(100 \% / 0 \%)$ & \pm 0.06 & \pm 1.0 & \pm 0.08 & \pm 2.2 \\
\hline $\mathrm{N}_{2} / \mathrm{O}_{2}$ & 0.90 & 21.7 & 0.62 & 12.2 \\
$(90 \% / 10 \%)$ & \pm 0.03 & \pm 0.8 & \pm 0.05 & \pm 1.3 \\
\hline $\mathrm{N}_{2} / \mathrm{O}_{2}$ & 0.96 & 22.8 & 0.67 & 14.5 \\
$(85 \% / 15 \%)$ & \pm 0.03 & \pm 2.0 & \pm 0.04 & \pm 1.4 \\
\hline $\mathrm{N}_{2} / \mathrm{O}_{2}$ & 0.97 & 20.1 & 0.66 & 12.8 \\
$(80 \% / 20 \%)$ & \pm 0.02 & \pm 1.6 & \pm 0.01 & \pm 1.2 \\
\hline $\mathrm{N}_{2} / \mathrm{O}_{2}$ & 0.97 & 21.0 & 0.64 & 13.0 \\
$(75 \% / 25 \%)$ & \pm 0.03 & \pm 1.7 & \pm 0.06 & \pm 1.5 \\
\hline
\end{tabular}

The incorporation of a small amount of oxygen during HCVD process is effective in passivating the trap states in MAPI. However, incorporation of excessive oxygen may lead to the creation of defect states which may be responsible for the slight reduction in the photovoltaic performance of the devices with MAPI prepared in the ambient of $\mathrm{N}_{2} / \mathrm{O}_{2}$ $(80 \% / 20 \%)$ and $\mathrm{N}_{2} / \mathrm{O}_{2}(75 \% / 25 \%)$ compared to the devices with MAPI grown in optimal composition of $\mathrm{N}_{2} / \mathrm{O}_{2}$ $(85 \% / 15 \%)$. Photothermal deflection spectroscopy (PDS) was conducted to investigate this observation and the results will be discussed in the latter text.

We have examined the impact of the post-deposition cooling rate on the film morphology. SEM pictures of MAPI films grown by HCVD technique under different conditions (Figure 2) show that HCVD-grown films with fast cooling rate, at $8^{\circ} \mathrm{C} /$ min (Figure 2a and $2 \mathrm{~b}$ ), demonstrate high concentration of pinholes which is substantially reduced when the cooling rate decreases to $4^{\circ} \mathrm{C} / \mathrm{min}$ (Figure $2 \mathrm{c}$ and 2d). Films with a slow cooling rate at $0.7^{\circ} \mathrm{C} /$ min (Figure 2e, 2f) demonstrate highly uniform and compact films with large crystal size ranging from $\sim 300 \mathrm{~nm}$ to $>\sim 1.5 \mu \mathrm{m}$ and the lowest pinhole concentration among the three types of films. This is consistent with work by Sriram et al. ${ }^{21}$ on perovskite-oriented $\left(\mathrm{Pb}_{0.92} \mathrm{Sr}_{0.08}\right)\left(\mathrm{Zr}_{0.65} \mathrm{Ti}_{0.35}\right) \mathrm{O}_{3}$ thin films who demonstrated that a lower post-deposition cooling rate resulted in the reduction of stress and an increase in the degree of orientation for the film. Such pinholes significantly affect the optoelectronic properties of the devices due to the high concentration of recombination centers. Furthermore, shorts between the electrodes may develop through the pinholes. The SEM images in Figure 2 show that the carrier gas composition has no obvious effects on the morphology of the MAPI films. The results stipulate that the function of the oxygen is to passivate the defect states rather than enhancing the crystallization of the material. On the other hand, slow 
cooling rates facilitates the formation of larger crystals. Figure $2 \mathrm{~g}$ and $2 \mathrm{~h}$ demonstrate superior crystal quality of the slow-cooled HCVD grown film. The PSC devices based on slow-cooled HCVD-grown MAPI layer is expected to exhibit substantial enhancement in device performance.

We have characterized the minority carrier lifetimes by analyzing the time resolved photoluminescence (TRPL) signals from the perovskite samples. From Figure 3a, six different types of MAPI films, with thickness $420 \mathrm{~nm} \pm 10 \mathrm{~nm}$, were investigated: i.) $\mathrm{N}_{2}$ carrier gas and cooling rate of $\sim 8^{\circ} \mathrm{C} / \mathrm{min}$ (type 1); ii.) $\mathrm{N}_{2}$ carrier gas and cooling rate of $\sim 4^{\circ} \mathrm{C} / \mathrm{min}$ (type 2); iii.) $\mathrm{N}_{2}$ carrier gas and cooling rate of $\sim 0.7^{\circ} \mathrm{C} / \mathrm{min}$ (type 3); iv.) optimal carrier gas and cooling rate of $\sim 8^{\circ} \mathrm{C} / \mathrm{min}$ (type 4); v.) optimal carrier gas and cooling rate of $\sim 4^{\circ} \mathrm{C} / \mathrm{min}$ (type 5); and vi.) optimal carrier gas and cooling rate of $\sim 0.7^{\circ} \mathrm{C} / \mathrm{min}$ (type 6). The TRPL data are fitted to a bi-exponential decay function, in which two distinct lifetimes $\tau_{1}$ and $\tau_{2}$ can be determined from the data. Significant improvements in the minority carrier lifetimes for films grown using $\mathrm{N}_{2} / \mathrm{O}_{2}$ mixture carrier gas instead of pure $\mathrm{N}_{2}$ are observed. It is believed that the oxygen in the carrier gas passivates the defects in MAPI and, thereby, reducing defect-assisted recombination. Films grown at post-deposition cooling rate of $0.7^{\circ} \mathrm{C} / \mathrm{min}$ also resulted in the enhancement of the carrier lifetime. This stipulates the reduction of the material defects due to enhancement in the crystal dimension. From the TRPL data, it is estimated that the carrier diffusion length for our optimized sample can be higher than $3 \mu \mathrm{m}$.

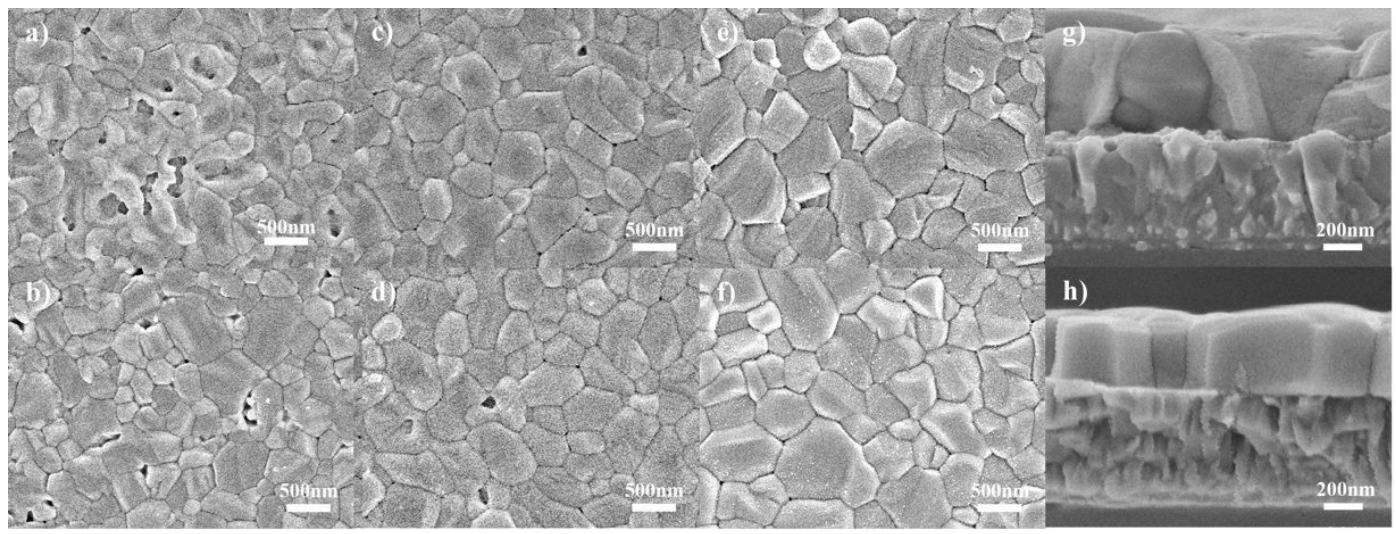

Figure 2. SEM images of MAPI films grown in $\mathrm{N}_{2}$ (a.; c.; and e.) and $\mathrm{O}_{2} / \mathrm{N}_{2}(15 \% / 85 \%$ ) (b.; d.; f.; g.; and h.) and at cooling rates $8^{\circ} \mathrm{C} / \mathrm{min}$ (a.; b.; and g.); $4^{\circ} \mathrm{C} / \mathrm{min}$ (c. and d.) and $0.7^{\circ} \mathrm{C} / \mathrm{min}$ (e.; f; and h.)
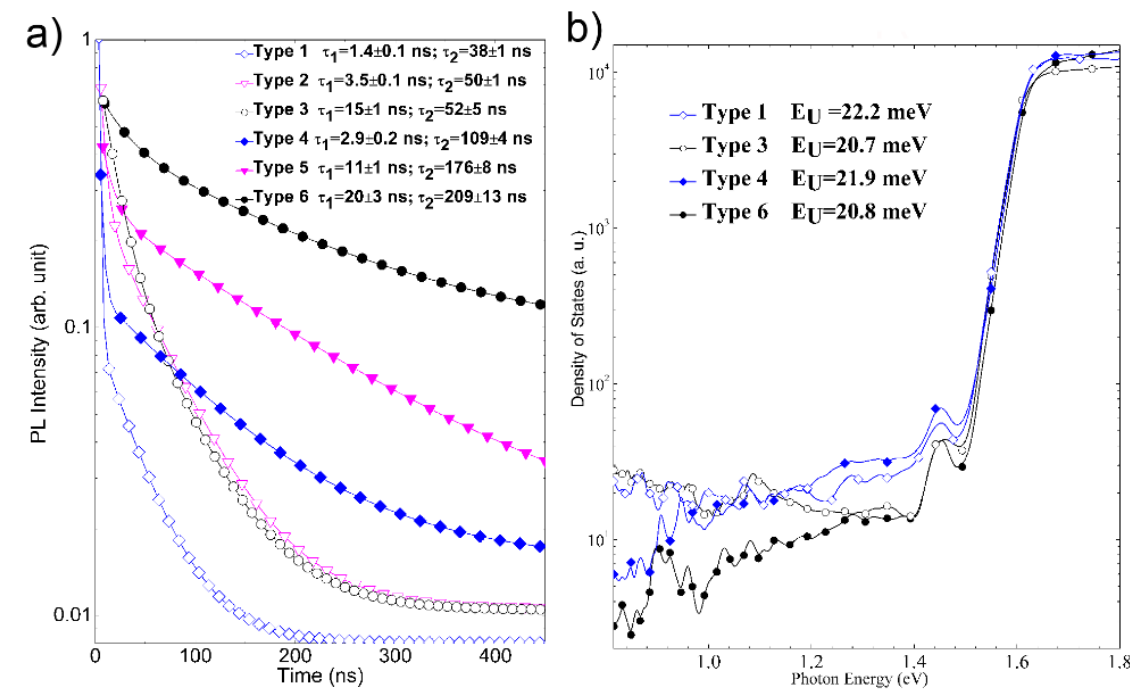

Figure 3. a) TRPL data and b) PDS spectra for different types of MAPI samples. 
We have examined the PDS for different types of MAPI films. The technique of PDS can detect the changes in the thermal state of the samples due to the nonradiative relaxation of photo-excited carriers with a high sensitivity of the order of $10^{-4}$. It is useful tool for the characterization of the energetic disorder such as the exponential decay of the absorption below the bandgap with a characteristic Urbach energy $\left(\mathrm{E}_{\mathrm{U}}\right)^{22}$. The technique has been widely utilized for analyzing electronic defects in amorphous and organic semiconductors ${ }^{23}$. In this work, four different types of samples were studied (types 1, 3, 4 and 6) and the results are presented in Figure 3b. It is observed that the bandgap is approximately $1.59 \mathrm{eV}$ in agreement with existing reports. The shallow traps are classified within the energy range of 15 $\mathrm{meV}$ from the conduction band edge, while the deep levels are the bandgap states that are at least $\sim 0.15 \mathrm{eV}$ from the band edge.

The shallow traps can be characterized by $\mathrm{E}_{\mathrm{U}}$ which reflects the steepness of the band tail states located at the conduction band edge. The $\mathrm{E}_{\mathrm{U}}$ for samples 1, 3, 4 and 6 are $22.2 \mathrm{meV}, 20.7 \mathrm{meV}, 21.9 \mathrm{meV}$ and $20.8 \mathrm{meV}$ respectively. The $\mathrm{E}_{\mathrm{U}}$ shows strong dependence on the cooling rates of the samples demonstrating significant reduction by $1.5 \mathrm{meV}$ and $1.1 \mathrm{meV}$ for slow-cooled samples (types 3 and 6) compared to their fast-cooled counterparts (types 1 and 4). Recent work by Yin et al. ${ }^{1}$ showed that $\mathrm{O}$ can passivate the shallow traps at the grain boundaries for MAPI films which is consistent with our experimental results. Furthermore, the cooling rate show significant impact on the defect densities of the films. We next consider the effects of the growth conditions on the deep traps. Types 3 film demonstrate substantial reduction in the trap density between $1.24 \mathrm{eV}$ to $1.45 \mathrm{eV}$ compared to type 1 film. Similarly, comparing type 4 film also show significant reduction in the deep traps between $0.8 \mathrm{eV}$ to $1.08 \mathrm{eV}$ compared to type $1 \mathrm{film}$. It is interesting to point out that for type 6 film, in which both the optimal carrier gas and slow cooling rate are used, deep traps over the entire energy range from $0.8 \mathrm{eV}$ to $1.45 \mathrm{eV}$ exhibit substantial reduction. Thus, the experimental results clearly show that both carrier gas ambient and the cooling rates have strong influences in the density of the deep traps. It is believed that there are two competing processes for the incorporation of oxygen during the HCVD growth. In addition to the effect of oxygen passivation, oxygen can be also regarded as a $p$ type dopant in MAPI. Incorporation of excessive oxygen into the material will create additional traps in MAPI, which is analogous to the case of excess dopants in semiconductors.

Meanwhile, low-frequency excess noise was measured on different types of MAPI films grown under the conditions: i.) MAPI films grown by two-step solution technique and without oxygen post-deposition annealing (type A); ii.) MAPI films grown by two-step solution technique with post-deposition oxygen annealing (type B); iii.) MAPI films grown by HCVD technique using pure nitrogen as the carrier gas (type C); and iv.) MAPI films grown by HCVD technique using $\mathrm{N}_{2} / \mathrm{O}_{2}(85 \% / 15 \%)$ mixture as the carrier gas (type D). Low-frequency noise measurement is a non-destructive characterization technique performed directly on the complete device structure. It has been shown that the low-frequency noise in a semiconductor device arises from the modulation of the device conductance due to the random capture and emission of carriers by localized states in the device ${ }^{24}$. Under a constant voltage bias the current fluctuation due to a single trap gives rise to a random telegraph noise with a power spectral density in the form of a Lorentzian, $\frac{\tau}{1+\omega^{2} \tau^{2}}$.

Since the individual trapping and detrapping events are statistically independent the total current noise power spectral density, $S_{I}(f)$, of the complete device is given by

$$
S_{I}(f)=4\left(\Delta I_{0}\right)^{2} \int_{E} \int_{z} \int_{y} \int_{x} N_{T}(E, x, y, z) \frac{\tau}{1+4 \pi^{2} f^{2} \tau^{2}} d x d y d z d E
$$

in which $\Delta I_{0}$ is the current fluctuation arising from the capture of a single carrier under constant voltage bias. The Lorentzian peaks sharply at $E_{p}=-k_{B} T \ln \left(\omega \tau_{0}\right)$ and the trap density can be expressed as $N_{T}\left(E_{p}\right) \approx \frac{4 C f}{k_{B} T} S_{I}(f, T)$ where $C$ is a proportionality constant and is related to the magnitude of the fluctuation in the conductance of the resistive structure due to: i.) modulation of the local carrier concentration at the vicinity of the trap; ii.) fluctuation in the carrier mobility arising from the changes of the Coulombic scattering rate due to the fluctuation in the density of the fixed charged states, ${ }^{25}$ and iii.) fluctuation in the current arising from the modulation of the energy barrier at various heterojunctions ${ }^{26}$ such as the $\mathrm{TiO}_{2} /$ perovskite interface, metal/perovskite interface and the grain boundaries. Despite the complicated picture underlying the quantitative evaluation of the conductance fluctuation for our samples, the exact magnitudes of $C$ should bear little consequences on the conclusion of our investigations as we are only interested in the relative changes in the trap density of the perovskite layer due to the various growth techniques. The normalized trap 
densities can be determined for the samples based on Eq. 1. The results (Figure 4) demonstrate significant reduction in the trap density due to post-deposition oxygen annealing (type B) for solution processed samples and the use of a carrier gas consisting of an $\mathrm{N}_{2} / \mathrm{O}_{2}(85 \% / 15 \%)$ mixture (type $\mathrm{D}$ ) in $\mathrm{HCVD}$ growth process.

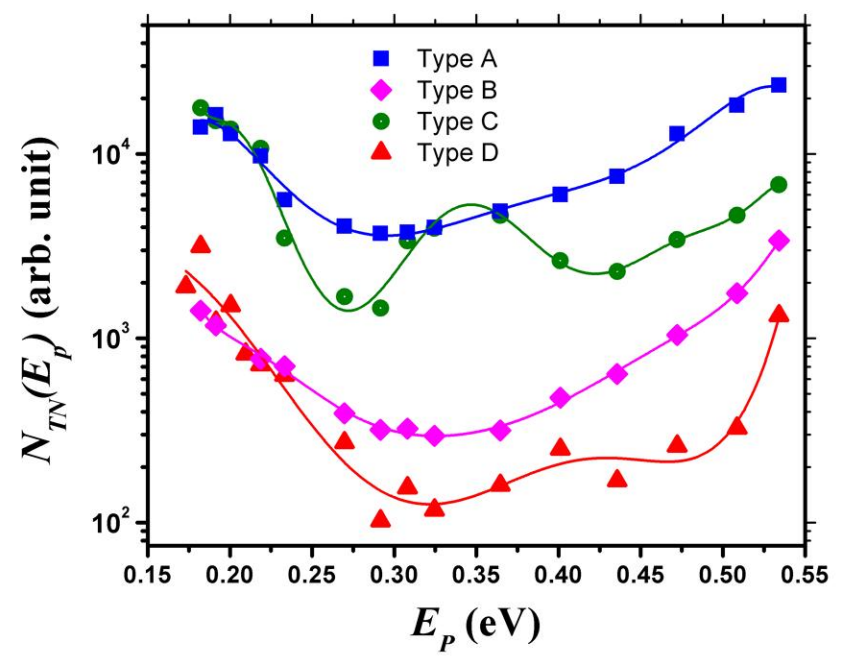

Figure 4. Normalized trap density for the different types of samples of resistive structures as a function of energy.

Standard planar devices were fabricated using HCVD-grown perovskite films with different post-deposition cooling rates in the optimized ambient. The corresponding optoelectronic properties are summarized in Table 2 . It is found that the average PCE of the devices increased significantly for the MAPI layers grown in $\mathrm{N}_{2} / \mathrm{O}_{2}(85 \%: 15 \%)$ and with a slow cooling rate of $0.7^{\circ} \mathrm{C} / \mathrm{min}$. It is found that the shunt resistance of the planar devices increases when the post-deposition cooling rate is reduced from $8^{\circ} \mathrm{C} / \mathrm{min}$ to $0.7^{\circ} \mathrm{C} / \mathrm{min}$, indicating less shunting paths in the slow-cooled MAPI devices as lowering the cooling rate is desired for MAPI crystallization with reduction in the concentration of pinholes. The reverse saturation current density $\left(J_{o}\right)$ is reduced with the reduction in the post-deposition cooling rate. The characterizations performed on the MAPI material and the corresponding devices show that the optimal growth ambient and proper thermal profile management are critical factors for the HCVD process to yield high quality MAPI films with low defect density. The best planar device fabricated utilizing the optimal fabrication parameters as presented above is shown to have a PCE of $17.2 \%$.

Table 2: The summary of photovoltaic performance of HCVD based solar cells. The values were averaged from 7 devices.

\begin{tabular}{|c|c|c|c|c|c|c|c|c|}
\hline Structure & $\begin{array}{c}\text { Cooling } \\
\text { Rate } \\
\left({ }^{\circ} \mathrm{C} / \mathrm{min}\right)\end{array}$ & $V_{O C}(\mathrm{~V})$ & $\begin{array}{c}J_{S C} \\
\left(\mathrm{~mA} / \mathrm{cm}^{2}\right)\end{array}$ & FF & PCE $(\%)$ & $R_{S}\left(\Omega \mathrm{cm}^{2}\right)$ & $\begin{array}{c}R_{S H} \\
\left(\mathrm{k} \Omega \mathrm{cm}^{2}\right)\end{array}$ & $\begin{array}{c}J_{o} \\
\left(\mathrm{~mA} / \mathrm{cm}^{2}\right)\end{array}$ \\
\hline \multirow{3}{*}{ Planar } & 8 & $0.97 \pm 0.02$ & $22.8 \pm 0.6$ & $0.66 \pm 0.02$ & $14.6 \pm 0.6$ & $7 \pm 3$ & $15 \pm 5$ & $1 \times 10^{-8}$ \\
\cline { 2 - 9 } & 4 & $1.01 \pm 0.03$ & $22.7 \pm 1.0$ & $0.67 \pm 0.02$ & $15.5 \pm 0.3$ & $7 \pm 3$ & $18 \pm 9$ & $2 \times 10^{-10}$ \\
\cline { 2 - 9 } & 0.7 & $1.00 \pm 0.02$ & $23.3 \pm 0.4$ & $0.72 \pm 0.01$ & $16.7 \pm 0.4$ & $7 \pm 1$ & $24 \pm 1$ & $1 \times 10^{-10}$ \\
\hline Mesoporous & 8 & $0.99 \pm 0.02$ & $23.2 \pm 0.6$ & $0.68 \pm 0.02$ & $15.5 \pm 0.3$ & $13 \pm 6$ & $15 \pm 2$ & $5 \times 10^{-8}$ \\
\cline { 2 - 8 } & 4 & $1.00 \pm 0.02$ & $23.2 \pm 0.4$ & $0.69 \pm 0.01$ & $16.1 \pm 0.4$ & $14 \pm 5$ & $19 \pm 6$ & $2 \times 10^{-8}$ \\
\cline { 2 - 8 } & 0.7 & $0.99 \pm 0.01$ & $23.1 \pm 0.4$ & $0.75 \pm 0.02$ & $17.2 \pm 0.2$ & $12 \pm 5$ & $35 \pm 5$ & $1 \times 10^{-12}$ \\
\hline
\end{tabular}

Device performance can be enhanced by improving the device structure. Photovoltaic devices utilizing an $\mathrm{mp}-\mathrm{TiO}_{2}$ scaffold were fabricated. We have conducted X-ray diffraction (XRD) characterizations of the perovskite films deposited 
on the glass $/ \mathrm{FTO} / \mathrm{c}-\mathrm{TiO}_{2}$ and glass $/ \mathrm{FTO} / \mathrm{c}-\mathrm{TiO} 2 / \mathrm{mp}-\mathrm{TiO}_{2}$ substrates. The diffraction peaks, as indicated in Fig. 5, which are attributed to the perovskite planes (110), (220) and (310) can be clearly resolved from the samples. The crystallinity of the material can be evaluated from the XRD data by computing the ratio between the integrated intensity under the crystalline peaks and the integrated intensity under the complete X-ray diffraction spectrum. It is found that perovskites grown by HCVD process on $\mathrm{mp}-\mathrm{TiO}_{2}$ substrates exhibit improvement in the crystallinity. Systematic studies on the impact of the mesoporous scaffold on the PV characteristics of the PSC had been carried out and the results are illustrated in Table 2 above. The results demonstrate significant enhancements in the device characteristics, particularly in the FF of the devices. Figure 6 shows the $I-V$ characteristics of the champion device utilizing the HCVD-grown MAPI under optimal processing conditions with the $\mathrm{mp}-\mathrm{TiO}_{2}$ scaffold. A champion device with $V_{O C}=1.0 \mathrm{~V}, J_{S C}=23.0$ $\mathrm{mA} / \mathrm{cm}^{2}, \mathrm{FF}=0.77$ and a high PCE of $17.6 \%$ was obtained It is clearly shown that the device exhibits high FF with little hysteresis, which is believed to arise from effective control of the defect density and enhancement in crystallization by using optimized perovskite growth methods as well as the effective extraction of the photocarriers due to the presence of mesoporous structure. Similar observation in the elimination of the hysteresis by reducing the density of traps in the MAPI was also reported by Lee et al. ${ }^{27}$

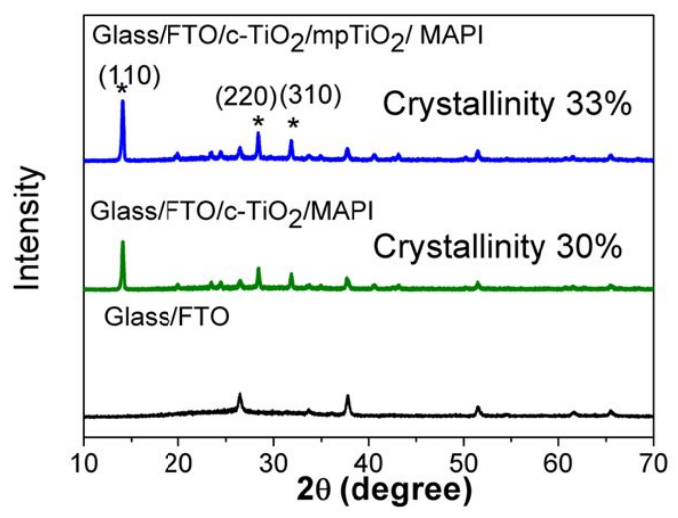

Figure 5. The XRD data for MAPI films prepared by the HCVD technique on different substrates.

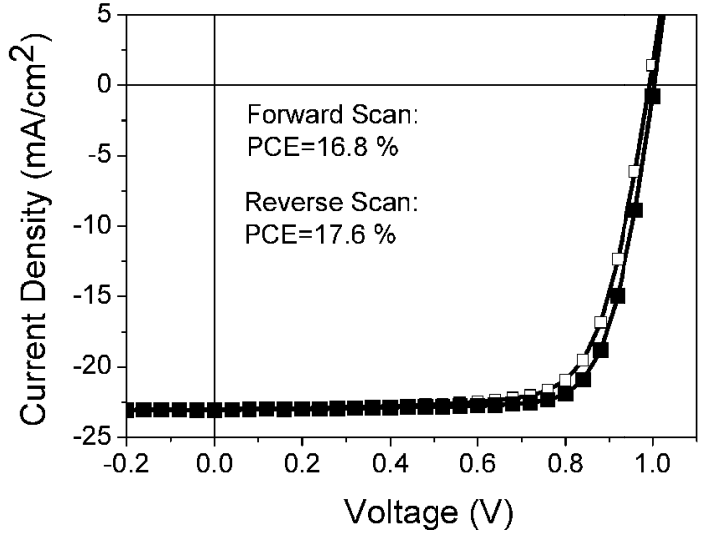

Figure 6. The $I-V$ characteristics of the optimized HCVD based device in mesoporous structure.

\section{CONCLUSION}

We have demonstrated that high quality MAPI thin films can be grown by HCVD technique. The process facilitates complete separation of the precursors and, thereby, eliminating pre-mature crystallization of the MAPI material and enables the uniform distribution of nucleation sites. The films were grown in Si-processing furnaces that enable excellent controllability and repeatability of the processing parameters. In particular, the process enables the optimization of both the composition of the carrier gas and the thermal profile of the crystal growth process. From our experimental results a carrier gas consisting of $\mathrm{N}_{2} / \mathrm{O}_{2}(85 \% / 15 \%)$ and with a slow post-deposition cooling rate of $0.7^{\circ} \mathrm{C} / \mathrm{min}$ are crucial for the reduction of both the shallow traps and the deep levels in MAPI material. Incorporation of an $\mathrm{mp}-\mathrm{TiO}_{2} \mathrm{scaffold}$ in the device can further improve the device performance due to further improvement in the crystallinity of the MAPI and enhancement of the carrier transport properties of the devices, leading to higher FF. With the optimized fabrication conditions and device architecture, the champion device with $V_{O C}=1.0 \mathrm{~V}, J_{S C}=23.0 \mathrm{~mA} / \mathrm{cm}^{2}, \mathrm{FF}=0.77$ giving a PCE of $17.6 \%$ was obtained.

\section{ACKNOWLEDGEMENT}

This work was supported by GRF grants (Grant No. PolyU 152045/15E), (Grant No. PolyU 152468/16E) and the Clarea Au Endowed Professorship. 


\section{REFERENCES}

[1] Yin, W. J., Chen, H., Shi, T., Wei, S. H. and Yan, Y., "Origin of high electronic quality in structurally disordered $\mathrm{CH}_{3} \mathrm{NH}_{3} \mathrm{PbI}_{3}$ and the passivation effect of $\mathrm{Cl}$ and $\mathrm{O}$ at grain boundaries," Adv. Electron. Mater. 1(6), 1500044 (2015).

[2] International Energy Agency, “Annual energy outlook 2017,” 5 January 2017, <https://www.eia.gov/outlooks/aeo/> (3 January 2018).

[3] International Energy Agency, “2017 Key World Energy Statistics,” September 2017, $<$ https://www.iea.org/publications/freepublications/publication/KeyWorld2017.pdf >, (3 January 2018).

[4] Kojima, A., Teshima, K., Shirai, Y. and Miyasaka, T., "Organometal halide perovskites as visible-light sensitizers for photovoltaic cells," J. Am. Chem. Soc. 131 (17), 6050-6051 (2009).

[5] National Renewable Energy Laboratory, "Best research-cell efficiencies," 30 October 2017, $<$ https://www.nrel.gov/pv/assets/images/efficiency-chart.png> (3 January 2018).

[6] Im, J. -H., Lee, C. -R., Lee, J. -W., Park, S. -W. and Park, N. G., " $6.5 \%$ efficient perovskite quantum-dotsensitized solar cell," Nanoscale 3 (10), 4088-4093 (2011).

[7] Stranks, S. D., Eperon, G. E., Grancini, G., Menelaou, C., Alcocer, M. J., Leijtens, T., Herz, L. M., Petrozza, A. and Snaith, H. J., "Electron-hole diffusion lengths exceeding 1 micrometer in an organometal trihalide perovskite absorber," Science 342 (6156), 341-344 (2013).

[8] Jeon, N. J., Noh, J. H., Yang, W. S., Kim, Y. C., Ryu, S., Seo, J. and Seok, S. I., "Compositional engineering of perovskite materials for high-performance solar cells," Nature 517, 476-480 (2015).

[9] Chen, Q., Zhou, H., Hong, Z., Luo, S., Duan, H. S., Wang, H. H., Liu, Y., Li, G. and Yang, Y., "Planar heterojunction perovskite solar cells via vapor-assisted solution process," J. Am. Chem. Soc. 136(2), 622-625 (2014).

[10] Leyden, M. R., Ono, L. K., Raga, S. R., Kato, Y., Wang, S. and Qi, Y., "High performance perovskite solar cells by hybrid chemical vapor deposition," J. Mater. Chem. A 2(44), 18742-18745 (2014).

[11] Konstantakou, M., Perganti, D., Falaras, P. and Stergiopoulos, T., "Anti-solvent crystallization strategies for highly efficient perovskite solar cells," Crystals 7(10), 291 (2017).

[12] Yin, J., Qu, H., Cao, J., Tai, H., Li, J. and Zheng, N., "Vapor-assisted crystallization control toward high performance perovskite photovoltaics with over $18 \%$ efficiency in the ambient atmosphere," J. Mater. Chem. A 4(34), 13203-13210 (2016).

[13] Liu, M., Johnston, M. B. and Snaith, H. J. "Efficient planar heterojunction perovskite solar cells by vapour deposition," Nature 501, 395-398 (2013).

[14] Ng, A., Ren, Z., Shen, Q., Cheung, S. H., Gokkaya, H. C., Bai, G., Wang, J., Yang, L., So, S. K., Djurišić, A. B., Leung, W. W., Hao, J., Chan, W. K. and Surya. C., "Efficiency enhancement by defect engineering in perovskite photovoltaic cells prepared using evaporated $\mathrm{PbI}_{2} / \mathrm{CH}_{3} \mathrm{NH}_{3} \mathrm{I}$ multilayers," J. Mater. Chem. A 3(17), $9223-$ 9231(2015).

[15] Djurišić, A. B., Liu, F. Z., Tam, H. W., Wong, M. K., Ng, A., Surya, Chen, C. W. and He, Z. B, "Perovskite solar cells - an overview of critical issues," Prog. Quantum Electron. 53, 1-37 (2017).

[16] Bakr, Z. H., Wali, Q., Fakharuddin, A., Schmidt-Mende, L., Brown, T. M. and Jose, R., "Advances in hole transport materials engineering for stable and efficient perovskite solar cells," Nano Energy 34, 271-305 (2017).

[17] Jeon, N. J., Noh, J. H., Kim, Y. C., Yang, W. S., Ryu, S. and Seok, S. I., "Solvent engineering for highperformance inorganic-organic hybrid perovskite solar cells," Nat. Mater. 13, 897-903 (2014).

[18] Li, X., Bi, D., Yi, C., Décoppet, J.-D., Luo, J., Zakeeruddin, S. M., Hagfeldt, A. and Grätzel, M. "A vacuum flashassisted solution process for high-efficiency large-area perovskite solar cells," Science 353(6294), 58-62 (2016).

[19] Ng, A., Ren, Z., Shen, Q., Cheung, S. H., Gokkaya, H. C., So, S. K., Djurišić, A. B., Wan, Y., Wu, X. and Surya, C. "Crystal engineering for low defect density and high efficiency hybrid chemical vapor deposition grown perovskite solar cells," ACS Appl. Mater. Interfaces 8 (48), 32805-32814 (2016).

[20] Conings, B., Drijkoningen, J., Gauquelin, N., Babayigit, A., D'Haen, J., D'Olieslaeger, L., Ethirajan, A., Verbeeck, J., Manca, J., Mosconi, E., Angelis, F. D. and Boyen, H. -G., "Intrinsic thermal instability of methylammonium lead trihalide perovskite," Adv. Energy Mater. 5(15), 1500477 (2015).

[21] Sriram, S., Bhaskaran, M. and Holland, A. S., "The effect of post-deposition cooling rate on the orientation of piezoelectric $\left(\mathrm{Pb}_{0.92} \mathrm{Sr}_{0.08}\right)\left(\mathrm{Zr}_{0.65} \mathrm{Ti}_{0.35}\right) \mathrm{O}_{3}$ thin films deposited by $\mathrm{RF}$ magnetron sputtering," Semicond. Sci. Technol. 21(9), 1236-1243 (2006). 
[22] Wolf, S. D., Holovsky, J., Moon, S. -J., Löper, P., Niesen, B., Ledinsky, M., Haug, F. -J., Yum, J. -H. and Ballif, C., "Organometallic halide perovskites: sharp optical absorption edge and its relation to photovoltaic performance," J. Phys. Chem. Lett. 5(6), 1035-1039 (2014).

[23] Goris, L., Poruba, A., Purkrt, A., Vandewal, K., Swinnen, A., Haeldermans, I., Haenen, K., Manca, J. V. and Vaněček, M., "Optical absorption by defect states in organic solar cells," J. Non-Cryst. Solids 352(9-20), 16561659 (2006).

[24] Surya, C. and Hsiang, T. Y., "A Thermal activation model for 1/f $f^{\gamma}$ noise in Si-MOSFETs," Solid-State Electron," 31(5), 959-964 (1988).

[25] Surya, C. and Hsiang, T. Y., "Surface mobility fluctuations in metal oxide-semiconductor field-effect transistors," Phys. Rev. B 35 (12), 6343-6347 (1987).

[26] Surya, C., Ng, S. H., Brown, E. R. and Maki, P. A., "Spectral and random telegraph noise characterizations of lowfrequency fluctuations in $\mathrm{GaAs} / \mathrm{Al}_{0.4} / \mathrm{Ga}_{0.6}$ as resonant tunneling diodes," IEEE Trans. Electron Devices 41(11), 2016-2022 (1994).

[27] Lee, J.-W., Kim, S.-G., Bae, S.-H., Lee, D.-K., Lin, O., Yang, Y. and Park, N.-G., "The interplay between trap density and hysteresis in planar heterojunction perovskite solar cells," Nano Lett. 17(7), 4270-4276 (2017). 